\title{
Comparison of Photoaddition Reactions of Aromatic Carbonyl Compounds with Silyl Thioketene Acetal vs. Silyl Ketene Acetal
}

\author{
In Ok Lee, Ung Chan Yoon*, Dae Won $\mathrm{Cho}^{+}$
}

Department of Chemistry and Chemistry Institute for Functional Materials, Pusan National University, Busan 609-735, Korea

+Deparrtment of Chemistry, Yeungnam University, Geoungsan, Geoungbuk 712-749, Korea

\begin{abstract}
Photoaddition reactions of aromatic carbonyl compounds with silyl thioketene acetals have been explored. The results of this study show that the acetonphenone react with dimethyl substituted silyl thioketene acetal competitively via either single electron transfer (SET)-desilylation or $[2+2]$-cycloaddition pathways to produce b-hydroxyester and oxetanes. In contrast, photochemical reactions of the benzaldehyde with dimethyl substituted silyl thioketene acetal mainly lead to the formation of oxetanes arising by [2+2] cycloaddition. A comparison of the results with those of silyl ketene acetal revealed that replacement of sulfur atom in a-silyl donor substrate bring about dramatic changes in chemoselectivities as well as excited state reaction mechanism.
\end{abstract}

In the area of single electron transfer (SET)-photochemistry, we have shown that sequential SET-desilylation reactions of a-silyl electron donors serve as highly efficient and regioselective methods to generate carbon-centered free radicals.1-7 (Scheme 1)

\section{Scheme 1}

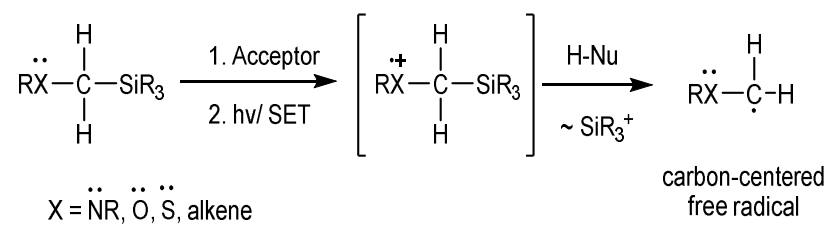

Recently, our efforts have focused on SET-promoted Mukaiyama type addition reactions between aromatic

*To whom correspondence should be addressed.

E-mail: ucyoon@pusan.ac.kr carbonyl compounds and silyl ketene acetal or silyl enol ether systems8-11. The results of these studies showed that photoaddition products arising by either SET-desilylation process or [2+2]-cycloaddition process are highly dependent on redox properties of a-silyl electron donor and solvent polarities. Especially, when electron rich, a-silyl donor and polar solvent (i.e., $\mathrm{MeCN}$ ) were used, photoreactions with aromatic carbonyl compounds lead to predominant formation of $\beta$-hydroxyketone/ $\beta$-hydroxyester via SET-desilylation pathways. However, oxetane formations were dominant in case of photoreaction of carbonyl compounds with a-silyl electron poor donor in less polar solvent (i.e., benzene). (Scheme 2)8-9

\section{Scheme 2.}

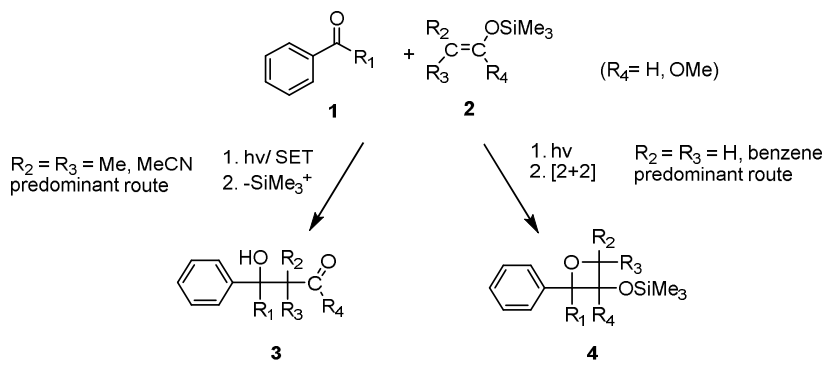

In this study, photoaddition reactions of carbonyl compounds 5-6 with silyl thioketene acetal (7) were explored and product profiles were compared with previously reported photoreactions of silyl ketene acetals.

Photochemical reactions were carried out by using Pyrex-filtered light in benzene solution of carbonyl compounds $(36 \mathrm{mM})$ and silyl thioketene acetal (72 $\mathrm{mM}$ ) for time periods that bring about $73-75 \%$ conversions of 5-6. The photolysates were subjected to chromatography to obtain photoproducts. Firstly, when benzene solution containing acetophenone (5) and 7 
was irradiated for $4 \mathrm{hr}, \beta$-hydroxythioester 8 (19\%), diasteromeric oxetanes $10 \mathrm{a}-10 \mathrm{~b} \quad(11 \%$ and $9 \%$ respectively) were produced along with $38 \%$ yield of reduction product 12. (Scheme 3 and Table 1) This result showed that SET-desilylation process vs Patero-Buchi type $[2+2]$-cycloaddition process compete each other in the excited state. When benzene solution containing benzaldehyde (6) and 7 was irradiated for $3 \mathrm{hr}$, $\beta$-hydroxyester 9, formed by SET-desilylation was obtained as a minor product (18\%) and diasteromeric oxetanes $11 \mathrm{a}-11 \mathrm{~b}$, arisen by $[2+2]$-cycloaddition were obtained as major products (totally $50 \%$ yield). (Scheme 3 and Table 1)

\section{Scheme 3.}

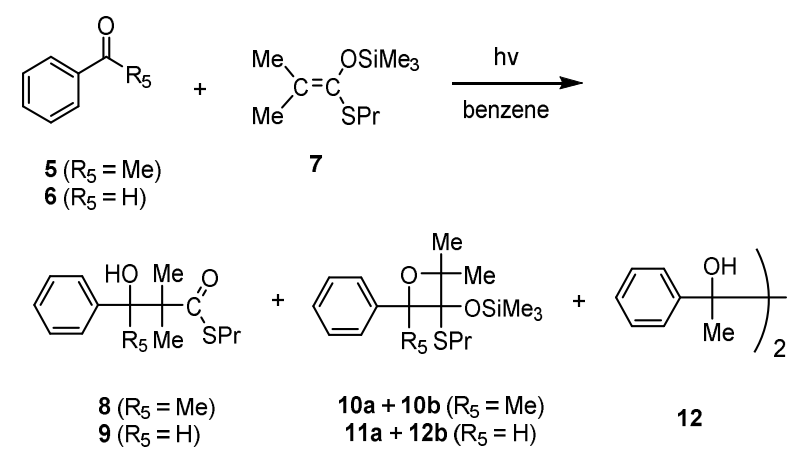

Table 1. Photoreactions of carbonyl compounds 5-6 and silyl thioketene acetal $7^{\text {a }}$

\begin{tabular}{cccc}
\hline Reactant & $\begin{array}{c}\text { Reaction } \\
\text { Time (h) }\end{array}$ & $\begin{array}{c}\text { Conversion } \\
(\%)\end{array}$ & Product (\% yield) \\
\hline $5+7$ & 4 & 71 & $\begin{array}{c}8(19), 10 a(11), \\
10 b(9), 12(38)\end{array}$ \\
$6+7$ & 3 & 75 & $\begin{array}{c}9(18), 11 \mathrm{a}(39), \\
11 \mathrm{~b}(11)\end{array}$ \\
\hline
\end{tabular}

${ }^{a}$ Concentrations of reactants, [carbonyl compound]/[7] are $36 / 72(\mathrm{mM})$.

${ }^{b}$ Yields are based on consumed carbonyl compounds 5-6.

A comparison of the photochemical reaction profiles of the silyl thioketene acetal 7, described above with that of the silyl ketene acetal 13 was made to find out if differences exist in the relative contributions of the SET vs. [2+2] cycloaddition pathways. In previous studies, 8 displayed in Scheme4 and Table2 it was found that photochemical reactions of 5-6 with silyl ketene acetal 13 gave rise to dominant formation of $\beta$-hydroxyester 14 via SET-desilylation process. (Scheme 4 and Table 2) These comparisons of product distributions revealed that replacement of sulfur atom from oxygen atom in a-silyl donor substrate could bring about dramatic changes in chemoselectivities as well as excited state reaction mechanism. In addition, photoreaction efficiencies (irradiation time vs conversion) were largely enhanced.

\section{Scheme 4.}

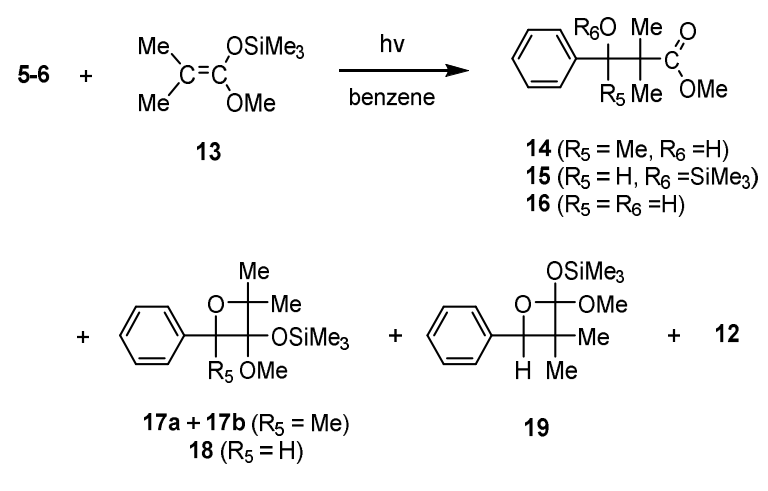

Table 2. Photoreactions of carbonyl compounds 5-6 and silyl ketene acetal $13^{\mathrm{a}}$

\begin{tabular}{cccc}
\hline Reactant & $\begin{array}{c}\text { Reaction } \\
\text { Time }(\mathrm{h})\end{array}$ & $\begin{array}{c}\text { Conversion } \\
(\%)\end{array}$ & Product (\% yield) \\
\hline $5+13$ & 33 & 77 & $\begin{array}{c}14(64), 17 a(11), \\
18 b(7), 12(3)\end{array}$ \\
$6+13$ & 11 & 79 & $\begin{array}{c}15(72), 16(14), \\
18(8), 19(4)\end{array}$ \\
\hline
\end{tabular}

${ }^{\mathrm{a} C o n c e n t r a t i o n s}$ of reactants, [carbonyl compound]/[7] are $36 / 72(\mathrm{mM})$.

${ }^{b}$ Yields are based on consumed carbonyl compounds $5-6$.

As a preliminary study, we have conducted photoaddition reaction of carbonyl compounds with silyl thioketene acetal. The combined results of our previous and current studies demonstrated above show that chemoselectivities of photoreaction of carbonyl compounds are highly dependent on a-silyl donor substrates. Further studies are underway to find how silyl thioketene acetal governs reaction patterns and reaction efficiencies.

KEYWORDS: Photoaddition, Silyl thioketene acetal, SET-photochemistry, [2+2]-Cycloaddition

Received December 13, 2013; Accepted December 17, 2013 


\section{ACKNOWLEDGEMENT}

We are grateful to the National Research Foundation of Korea (NRF) funded by the Ministry of Education, Science, and Technology (2012R1A1A2007158 for UCY and 2012R1A1A1013201 for DWC) for support of this research.

\section{REFERENCES AND NOTES}

1. Yoshida, J.; Maekawa, T.; Murata, T.; Matsunaya, S.; Isoe, S. J. Am. Chem. Soc. 1990, 112, 1962-1970.

2. Yoshida, J.; Matsunaga, S.; Murata, T.; Isoe, S. Tetrahedron 1991, 47, 615-624.

3. Cooper, B. E.; Owen, W. J. J. Organomet. Chem. 1971, 29, 33-40.

4. Pitt, C. G. J. Organomet. Chem. 1973, 61, 49-70.

5. Zang, X. M.; Yeh, S. -R.; Hong, S.; Freccero, M.; Albini, A.; Falvey, D. E.; Mariano, P. S. J. Am. Chem. Soc. 1994, 116, 4211-4220.
6. Su, Z.; Mariano, P. S.; Falvey, D. E.; Yoon, U. C.; Oh, S. W. J. Am. Chem. Soc. 1998, 120, 10676-10686.

7. Cho, D. W.; Yoon, U. C.; Mariano, P. S. Acc. Chem. Res. 2011, 44, 204-215.

8. Yoon, U. C.; Kim, M. J.; Moon, J. J.; Oh, S. W.; Kim, H. J.; Mariano, P. S. Bull. Korean Chem. Soc. 2002, 23, 1218-1228.

9. Cho, D. W.; Lee, H. -Y.; Oh, S. W.; Choi, J. H.; Park, H. J.; Mariano, P. S.; Yoon, U. C. J. Org. Chem. 2008, 73, 4539-4547.

10. Oh, S. W.; Kim, J. Y.; Cho, D. W.; Choi, J. H.; Yoon, U. C. Bull. Korean Chem. Soc. 2007, $28,629-634$.

11. Park, H. J.; Yoon, U. C.; Lee, H. -Y.; Cho, D. W.; Mariano, P. S. J. Org. Chem. 2012, 77, 10304-10313. 